\title{
Synthesis and characterization of $\mathrm{ZnSe:} \mathrm{Ag} / \mathrm{SiO}_{2}$ nanoparticles
}

\author{
Fenghua Huang ${ }^{1, *}$, Tao Huang ${ }^{1}$, Xiangwei $\mathrm{Wu}^{1}$ and Wenhui Pang ${ }^{1}$ \\ ${ }^{1}$ College of Chemistry and Materials Science, Fujian Normal University, Fuzhou 350007, P.R. China
}

\begin{abstract}
Argentum-doped zinc selenide/silicon dioxide nanoparticles (expressed as $\mathrm{ZnSe}: \mathrm{Ag} / \mathrm{SiO}_{2}$ ) were synthesized by Stöber method. The structure, morphology and fluorescence properties of the quantum dots were characterized by X-ray powder diffraction, transmission electron microscopy, infrared spectrum, ultraviolet-visible spectrum and fluorescence spectrum. The results show that the as-prepared $\mathrm{ZnSe}: \mathrm{Ag} / \mathrm{SiO}_{2}$ nanoparticles are spherical, most of which are about $30 \mathrm{~nm}$ in size, and have good fluorescence properties. Compared with that of $\mathrm{ZnSe}: \mathrm{Ag}$ nanoparticles, the stability of $\mathrm{ZnSe}: \mathrm{Ag} / \mathrm{SiO}_{2}$ nanoparticles is enhanced obviously. The $\mathrm{ZnSe}: \mathrm{Ag} / \mathrm{SiO}_{2}$ nanoparticles will have potential applications in biological fluorescence analysis.
\end{abstract}

\section{INTRODUCTION}

II-VI group quantum dots (QDs), also known as semiconductor nanocrystals, have attracted much attention due to their unique physical and chemical properties, such as wide and continuous absorption spectrum, narrow and symmetrical emission spectrum and photochemical stability.[1-3] Over the years, II-VI group quantum dots have been widely used in biological analysis.[4-6] Zinc selenide (ZnSe) quantum dots are IIVI semiconductor fluorescence materials with low toxicity, wide band gap $(2.69 \mathrm{eV})$ and unique fluorescence properties, which are beneficial to their applications in the field of biological analysis[7]. In 2000, Meijerink et al. [8] reported for the first time that $\mathrm{Mn}$ doped $\mathrm{ZnSe}$ quantum dots synthesized by organometallic synthesis method had excellent fluorescence properties. The fluorescence properties of quantum dots can be improved by doping transition metal ions in the quantum dots.[9] However, in a complex biological environment, the molecules modified on the surface of quantum dots tend to fall off slowly, resulting in a decrease in the stability and fluorescence intensity of quantum dots, which is not conducive to the application of quantum dots in the complex environment.[10] Therefore, in order to improve the stability of the fluorescent quantum dots, it is a good solution to coat the surface of quantum dots with non-toxic, chemically inert and optically transparent silica shell layer. In addition, there are abundant hydroxyl functional groups on the surface of $\mathrm{SiO} 2$ shell, which can be modified by silane coupling agent to make the surface of nanoparticles contain amino groups, so as to better realize the application of nanoparticles in biomolecular detection. The method commonly used to prepare SiO2-coated nanoparticles is Stöber method, which has mild and simple synthesis conditions. For instance, the $\mathrm{SiO} 2$-coated zinc based nanoparticles (e.g. $\mathrm{ZnSe} / \mathrm{ZnS} / \mathrm{SiO}_{2}[11], \mathrm{ZnS}$ :
$\mathrm{Mn} / \mathrm{SiO}_{2}$ [12], $\mathrm{Mn} / \mathrm{ZnS} @ \mathrm{SiO}_{2}-\mathrm{NH}_{2}$ [13] and $\mathrm{ZnS} / \mathrm{SiO}_{2}$ [14]) were prepared by the Stober method. Up to now, to the best of our knowledge, the synthesis of $\mathrm{SiO}_{2}$-coated Agdoped $\mathrm{ZnS}$ nanoparticles (i.e. $\mathrm{ZnSe}: \mathrm{Ag} / \mathrm{SiO}_{2}$ ) by Sober method has not been reported. In this paper, $\mathrm{ZnSe}$ : $\mathrm{Ag} / \mathrm{SiO}_{2}$ nanoparticles were prepared by Stober method by coating $\mathrm{SiO}_{2}$ on $\mathrm{ZnSe}$ : Ag quantum dots reported in our laboratory [15], and the characterization and fluorescence properties of the $\mathrm{ZnSe}: \mathrm{Ag} / \mathrm{SiO}_{2}$ nanoparticles were studied.

\section{Experimental}

\subsection{Instruments and reagents}

The X-ray powder diffraction (XRD) patterns were performed by using an X'pert-MPD Model (Philips, Andover, MA). Infrared (IR) spectra were measured with an Equinox 55 FTIR spectrometer (Bruker, Bremen, Germany). The ultraviolet-visible (UV-Vis) spectra were obtained by a Cary 50 UV-visible spectrometer (Varian, Palo Alto, CA). Fluorescence spectra experiments were carried out by using an F-1000 spectrometer photometer (Hitachi, Chiyoda, Japan). Transmission electron microscope experiment were carried out by using a HT7700 Transmission Electron Microscope (Hitachi Corporation, Japan).

All the chemicals including Sodium borohydride $\left(\mathrm{NaBH}_{4}\right)$, Zinc acetate dihydrate $\left(\mathrm{Zn} \quad(\mathrm{Ac})_{2} \cdot 2 \mathrm{H}_{2} \mathrm{O}\right)$, Selenium (Se), Silver nitrate dihydrate $\left(\mathrm{AgNO}_{3} \cdot 2 \mathrm{H}_{2} \mathrm{O}\right)$, Lcysteine (L-Cys), Sodium hydroxide $(\mathrm{NaOH})$, tetraethoxy silane (TEOS), ammonium hydroxide $\left(\mathrm{NH}_{3} \cdot \mathrm{H}_{2} \mathrm{O}\right)$, 3aminopropyl triethoxy silane (APTES) and Anhydrous ethanol $\left(\mathrm{C}_{2} \mathrm{H}_{5} \mathrm{OH}\right)$ were purchased from Guoyao Chemical Reagent. The water used in this experiment is ultrapure water. The preparation of $0.05 \mathrm{mo} / \mathrm{L} \mathrm{NaHSe}$ solution was performed according to the procedure from

*corresponding author's e-mail address: fenghuahuang@fjnu.edu.cn 
the literature [16].

\subsection{Synthesis of $\mathrm{ZnSe}: \mathrm{Ag} / \mathrm{SiO}_{2}$ nanoparticles}

First, under a N2 atmospere, a certain amount of Lcysteine, $0.1 \mathrm{~mol} / \mathrm{L} \mathrm{Zn}(\mathrm{OAc})_{2}$ solution and $0.01 \mathrm{~mol} / \mathrm{L}$ AgNO3 solution were sequentially added into a three-neck flask under magnetic stirring, and the $\mathrm{pH}$ value of the mixed solution was adjusted to 10.0 by adding $2.0 \mathrm{~mol} / \mathrm{L}$ $\mathrm{NaOH}$ solution. When the temperature of oil bath was heated to $100^{\circ} \mathrm{C}$, a freshly prepared nitrogen-saturated solution of $0.05 \mathrm{~mol} / \mathrm{L} \mathrm{NaHSe}$ was quickly injected into the mixed solution and the reaction solution was subjected to a reflux for $1 \mathrm{hr}$ under vigorous stirring to obtain Lcysteine-modified ZnSe: Ag QDs colloidal solution. The solution was then cooled to $30^{\circ} \mathrm{C}$.

Then, L-cysteine modified $\mathrm{ZnSe}: \mathrm{Ag}$ quantum dots solution was added to a three-necked flask, the $\mathrm{pH}$ value of the solution was adjusted to 10.0 with $5 \mathrm{wt} \%$ ammonia water under magnetic stirring for 30 minutes, and a certain volume of tetraethyl orthosilicate solution (TEOS: ethanol $=1: 3$ ) and a certain volume of 3-aminopropyl triethoxysilane (APTES) solution were added. The above reaction mixture solution reacted in a water bath at $30^{\circ} \mathrm{C}$ for 12 hours to obtain $\mathrm{ZnSe}: \mathrm{Ag} / \mathrm{SiO}_{2}$ nanoparticle colloidal solution. The as-prepared colloidal solution was concentrated by a rotary evaporator and then purified by ethanol precipitation procedure to obtain purified $\mathrm{ZnSe}$ : $\mathrm{Ag} / \mathrm{SiO}_{2}$ nanoparticles powder.

\section{Results and discussion}

\subsection{XRD analysis}

The XRD patterns of the as-prepared L-cysteine-modified $\mathrm{ZnSe}: \mathrm{Ag}$ quantum dots and $\mathrm{ZnSe}: \mathrm{Ag} / \mathrm{SiO}_{2}$ nanoparticles are presented in Fig.1. Fig. 1a shows that the three diffraction peaks at $2 \theta=28.20^{\circ}, 46.54^{\circ}$ and $54.91^{\circ}$ correspond to the (111), (220) and (311) planes of the standard cubic crystalline ZnSe (JCPDS No.80-0021), respectively, which indicates that the as-prepared $\mathrm{ZnSe}$ : Ag quantum dots belong to the cubic zinc blende structure. It can be seen from Fig. $1 \mathrm{~b}$ that there are three diffraction peaks at $2 \theta=27.45^{\circ}, 46.47^{\circ}$ and $54.43^{\circ}$ corresponding to $\mathrm{ZnSe}$ : Ag quantum dots, and another wide diffraction peak at $2 \theta=23^{\circ}$ corresponding to amorphous silicon dioxide (JCPDS No. 29-0085) [17], which indicates that the $\mathrm{SiO}_{2}$ is coating on the surface of $\mathrm{ZnSe}$ : Ag quantum dots.

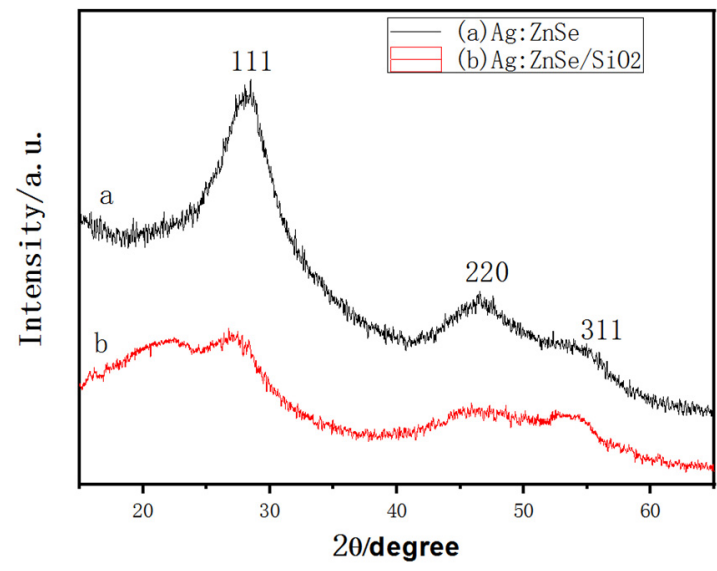

Figure 1. XRD patterns of L-cysteine-modified ZnSe: Ag quantum dots (a) and $\mathrm{ZnSe}: \mathrm{Ag} / \mathrm{SiO}_{2}$ nanoparticles (b)

\subsection{TEM analysis}

Fig.2 shows the TEM images of $\mathrm{ZnSe}: \mathrm{Ag} / \mathrm{SiO}_{2}$ nanoparticles. It can be seen that $\mathrm{Ag}$ : $\mathrm{ZnSe} / \mathrm{SiO}_{2}$ nanoparticles have a spherical structure with average particle size of about $30 \mathrm{~nm}$.

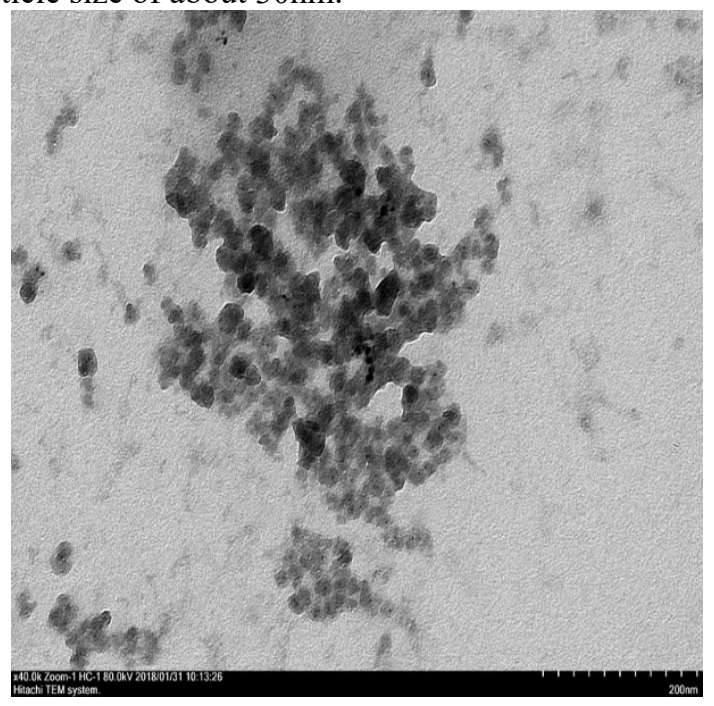

Figure 2. TEM image of the $\mathrm{ZnSe}: \mathrm{Ag} / \mathrm{SiO}_{2}$ nanoparticles

\subsection{Infrared spectrum analysis}

The Infrared spectra of $\mathrm{ZnSe}: \mathrm{Ag}$ quantum dots and $\mathrm{ZnSe}$ : $\mathrm{Ag} / \mathrm{SiO}_{2}$ nanoparticles are shown in Fig. 3 (a), it is can be found from Fig.3a, $\operatorname{IR}(\mathrm{KBr})$ : $3416.3 \mathrm{~cm}-1\left(v_{\mathrm{O}-\mathrm{H}}\right)$, $2924.4 \mathrm{~cm}-1\left(v_{\mathrm{N}-\mathrm{H}}\right), 1587.7 \mathrm{~cm}-1\left(v_{\mathrm{C}=\mathrm{O}}\right), 1409.4 \mathrm{~cm}-1\left(v_{\mathrm{C}=\mathrm{O}}\right)$, $1256.7 \mathrm{~cm}-1\left(v_{\mathrm{C}-\mathrm{O}}\right), 1060 \mathrm{~cm}-1\left(v_{\mathrm{C}-\mathrm{N}}\right)$ and $646 \mathrm{~cm}-1\left(v_{\mathrm{C}-\mathrm{S}}\right)$. From Fig. 3 b, it can be seen that the above vibration peaks have shifted slightly, and three new absorption peaks appeared at $1070 \mathrm{~cm}-1\left(v_{\mathrm{O}-\mathrm{Si}-\mathrm{O}}\right), \quad 921.3 \mathrm{~cm}-1\left(v_{\mathrm{Si}-\mathrm{OH}}\right)$, $463.9 \mathrm{~cm}-1\left(v_{\mathrm{Si}-\mathrm{O}}\right)$, respectively. The three new peaks are all characteristic peaks of silica, indicating that silica is successfully coated on the $\mathrm{ZnSe}$ : Ag quantum dots. 


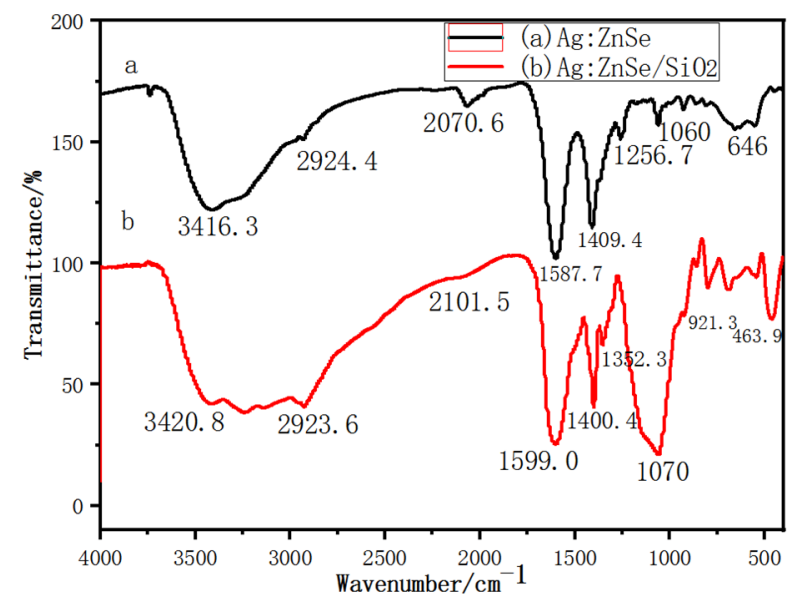

Figure 3. IR spectra of L-cysteine-modified ZnSe:Ag quantum dots (a) and $\mathrm{ZnSe}: \mathrm{Ag} / \mathrm{SiO}_{2}$ nanoparticles (b)

\subsection{UV-Vis absorption spectrum analysis}

Fig.4 shows the UV-Vis absorption spectra of the asprepared $\mathrm{ZnSe}$ : Ag quantum dots (a) and $\mathrm{ZnSe}: \mathrm{Ag} / \mathrm{SiO}_{2}$ nanoparticles (b). As can be seen from Fig.4, compared with the absorption edge of $\mathrm{ZnSe}$ : Ag quantum dots, the absorption edge of $\mathrm{ZnSe}: \mathrm{Ag} / \mathrm{SiO}_{2}$ nanoparticles show an obvious red shift, which is attributed to the quantum size effect. [18]

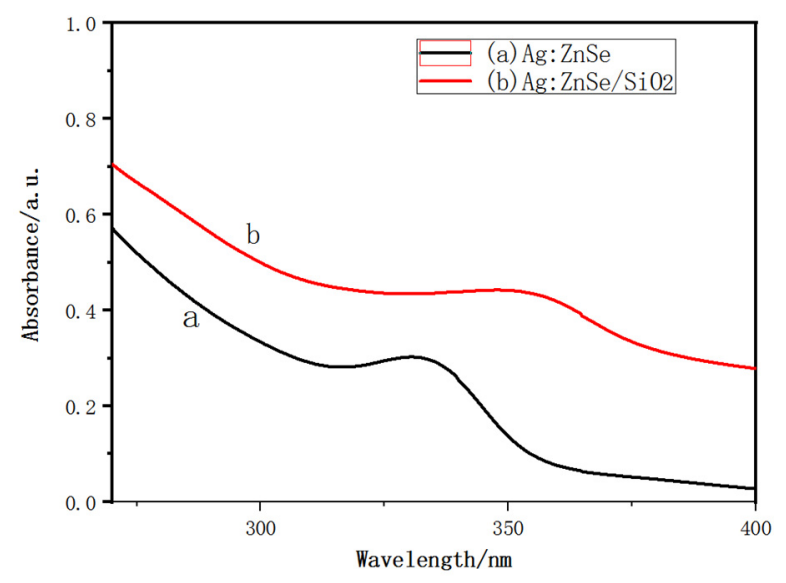

Figure 4. UV-Vis absorption spectra of $\mathrm{ZnSe}$ : Ag quantum dots (a) and $\mathrm{ZnSe}: \mathrm{Ag} / \mathrm{SiO}_{2}$ nanoparticles(b)

\subsection{Fluorescence spectrum analysis}

Fig.5 presents the fluorescence emission spectra of $\mathrm{ZnSe}$ : Ag quantum dots (a) and $\mathrm{ZnSe}: \mathrm{Ag} / \mathrm{SiO}_{2}$ nanoparticles (b). Fig.5a shows that $\mathrm{ZnSe}$ : Ag has a strong emission peak at $440 \mathrm{~nm}$. Compared with the emission peak of $\mathrm{ZnSe}: \mathrm{Ag}$ quantum dots, the emission peak of $\mathrm{ZnSe}: \mathrm{Ag} / \mathrm{SiO}_{2}$ shows a certain degree of red shift, while the fluorescence intensity decreases slightly. The red shift is caused by the formation of $\mathrm{SiO}_{2}$ shell. The decrease of fluorescence intensity may be due to the effect of $\mathrm{SiO}_{2}$ shell on the optical refractive index of the fluorescent quantum dot and the shielding effect on partial emitted light.[10]

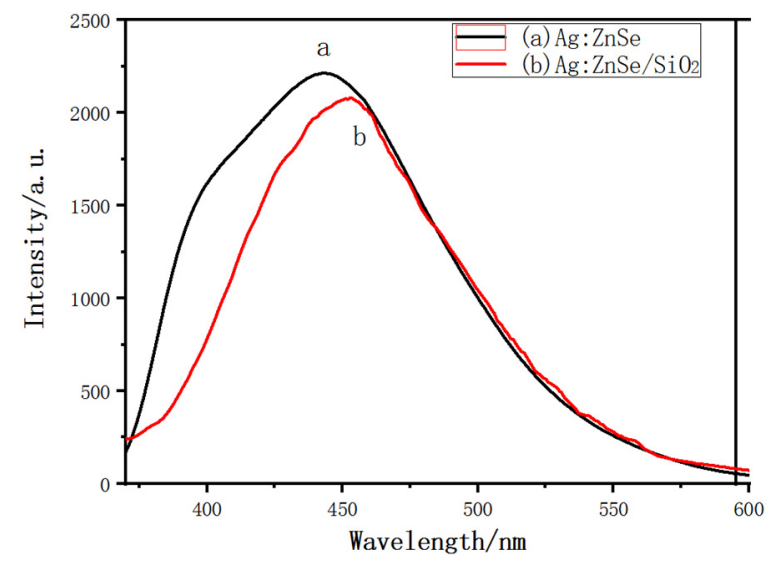

Figure 5. Fluorescence spectra of $\mathrm{ZnSe}$ quantum dots (a) and $\mathrm{ZnSe}: \mathrm{Ag} / \mathrm{SiO}_{2}$ nanoparticles (b)

\section{CONCLUSION}

In this paper, $\mathrm{ZnSe}: \mathrm{Ag} / \mathrm{SiO}_{2}$ composite nanoparticles are successfully prepared by Stöber method. X-ray powder diffraction analysis, transmission electron microscopy, infrared spectrum analysis, ultraviolet-visible absorption spectrum analysis and fluorescence spectrum analysis show that $\mathrm{SiO}_{2}$ is coated on $\mathrm{ZnSe}$ : Ag fluorescent quantum dots, and the $\mathrm{ZnSe}: \mathrm{Ag} / \mathrm{SiO}_{2}$ spherical composite nanoparticles with an average particle size of $30 \mathrm{~nm}$ have good fluorescence properties. The functional groups on the silicon dioxide shell of the composite nanoparticles will provide the possibility for the combination of the nanoparticle with biomacromolecules, which lays the foundation for their application in biological analysis.

\section{Acknowledgments}

This project was financially supported by the Nature Science Foundation of Fujian Province of China(2009J01022).

This work was supported by the 2020 undergraduate innovation and entrepreneurship training program of Fujian Normal University (cxxl-2020192).

\section{References}

1. Alivisatos, A. P. (1996) Semiconductor clusters, nanocrystals, and quantum dots. Science., 271: 933937.

2. Bruchez, M., Moronne, M., Gin, P., Weiss, S., Alivisatos, A. P. (1998) Semiconductor nanocrystals as fluorescent biological labels. Science, 281: 20132016.

3. Chan, W. C. W., Nie, S. (1998) Quantum dot bioconjugates for ultrasensitive nonisotopic detection. Science, 281: 2016-2018.

4. Mattoussi, H., Mauro, J. M., Goldman, E. R., Anderson, G. P., Sundar, V. C., Mikulec, F. V., Bawendi, M. G. (2000) Self-Assembly of CdSe-ZnS Quantum Dot Bioconjugates Using an Engineered Recombinant Protein. J. Am. Chem. Soc., 122: 


$$
\text { 12142-12150. }
$$

5. Zhang, B. H., Qi, L., Wu, F. Y. (2010) Functionalized manganese-doped zinc sulfide core/shell quantum dots as selective fluorescent chemodosimeters for silver ion. Microchimica Acta, 170: 147-153.

6. Hosseini, M., Ganjali, M. R., Vaezi, Z., Arabsorkhi, B., Dadmehr, M., Faridbod, F., and Norouzi, P. (2015) Selective recognition histidine and tryptophan by enhanced chemiluminescence $\mathrm{ZnSe}$ quantum dots. Sensors and Actuators B: Chemical, 210: 349-354.

7. Reiss, P. (2007) ZnSe based colloidal nanocrystals: synthesis, shape control, core/shell, alloy and doped systems. New J. Chem., 31: 1843-1852.

8. Suyver, J. F., Wuister, S. F., Kelly, J. J., and Meijerink, A. (2000) Luminescence of nanocrystalline $\mathrm{ZnSe}: \mathrm{Mn}^{2+}$. PCCP, 2: 5445-5448.

9. Bhargava, R. N., Gallagher, D., Hong, X., and Nurmikko, A. (1994) Optical properties of manganese-doped nanocrystals of ZnS. Phys. Rev. Lett., 72: 416-419.

10. Zhong, W. Y., Yang, S., Huang, B., Wei, X., Wu, Z.S., $\mathrm{Xu}$, D.K. (2012) Preparation of New Type $\mathrm{SiO}_{2}$ Microsphere Containing Controllable Number of $\mathrm{CdTe} / \mathrm{ZnS}$ and Its Application in Cell Imaging. Chinese Journal Of Inorganic Chemistry, 28: 23212328.(In Chinese).

11. Chen, X., Liu, F., Jiang, Q., Sun, L., and Wang, Q. (2011) Synthesis and Properties of Water-Soluble Silica-Coated $\mathrm{ZnSe} / \mathrm{ZnS}$ Semiconductor Quantum Dots. Journal of Inorganic and Organometallic Polymers and Materials, 22: 6-11.

12. Cao, J., Wang, T., Yang, J., Zhou, X., Han, D., Yang, S., Liu, Q., and Niu, H. (2014) Fabrication and optical properties of $\mathrm{ZnS}: \mathrm{Mn}^{2+}$ quantum dots/SiO2 nanocomposites. Journal of Materials Science: Materials in Electronics, 25: 4512-4516.

13. Zhong, Y., Wang, Q., He, Y., Ge, Y., and Song, G. (2015) Amino-functionalized silica-encapsulated $\mathrm{Mn} / \mathrm{ZnS}$ quantum dots for the room-temperature phosphorescence determination of graphene oxide in environmental water samples. Analytical Methods, 7: 7874-7878

14. Saavedra Rodriguez, G., Carrillo Torres, R. C., Sanchez Zeferino, R., and alvarez Ramos, M. E. (2019) Stabilized blue emitting $\mathrm{ZnS} @ \mathrm{SiO}_{2}$ quantum dots. Opt. Mater., 89: 396-401.

15. Lin, L. P., Huang, F. H., and Chen, P. F. (2014) Synthesis and fluorescence properties of watersoluble L-cysteine-modified ZnSe:Ag quantum dots, Advanced Materials Research ,Vols 10331034:1172-1175

16. Klayman, D. L.; Griffin, T. S.(1972) Reaction of Selenium with Sodium Borohydride in Protic Solvents. A Facile Method for the Introduction of Selenium into Organic Molecules. Journal of American Chemical, 95, 197-199.

17. Qu, H., Cao, L., Su, G., Liu, W., Gao, R., Xia, C., and Qin, J. (2014) Silica-coated ZnS quantum dots as fluorescent probes for the sensitive detection of $\mathrm{Pb}^{2+}$ ions. J. Nanopart. Res., 16.

18. Ma X. B., Nie W., Wang C., Zhang W.J., Ji X. L., J. (2010) Preparation and luminescent properties of $\mathrm{CdSe} / \mathrm{CdS} / \mathrm{SiO}_{2}$ composite nanospheres. Chemical Journal Of Chinese Universities, 31: 874-880.(In Chinese). 